\title{
BMJ Open Knowledge and perceptions of COVID-19, prevalence of pre-existing conditions and access to essential resources in Somali IDP camps: a cross- sectional study
}

\author{
Jude Alawa (D) , ${ }^{1}$ Samir Al-Ali, ${ }^{2}$ Lucas Walz, ${ }^{3}$ Eleanor Wiles, ${ }^{4}$ Nikhil Harle, ${ }^{2}$ \\ Mohamed Abdullahi Awale, ${ }^{5}$ Deqo Mohamed, ${ }^{6}$ Kaveh Khoshnood ${ }^{3}$
}

To cite: Alawa J, Al-Ali S, Walz L, et al. Knowledge and perceptions of COVID-19, prevalence of pre-existing conditions and access to essential resources in Somali IDP camps: a crosssectional study. BMJ Open 2021;11:e044411. doi:10.1136/ bmjopen-2020-044411

- Prepublication history for this paper is available online. To view these files, please visit the journal online (http://dx.doi. org/10.1136/bmjopen-2020044411).

Received 03 September 2020 Accepted 27 May 2021

Check for updates

(c) Author(s) (or their employer(s)) 2021. Re-use permitted under CC BY-NC. No commercial re-use. See rights and permissions. Published by BMJ.

${ }^{1}$ Stanford University School of Medicine, Stanford, California, USA

${ }^{2}$ Yale University, New Haven, Connecticut, USA

${ }^{3}$ Yale University School of Public Health, New Haven, Connecticut, USA

${ }^{4}$ Milken Institute of Public Health, The George Washington University, Washington, DC, USA ${ }^{5}$ SIMAD University, Mogadishu, Somalia

${ }^{6}$ Hagarla Institute, Mogadishu, Somalia

Correspondence to

Dr Kaveh Khoshnood;

kaveh.khoshnood@yale.edu

\section{ABSTRACT}

Objectives This study examined knowledge and perceptions of COVID-19, prevalence of pre-existing conditions and access to essential resources among residents of internally displaced person (IDP) camps in Somalia, where overcrowded settlements with weakened infrastructure, inadequate water, sanitation, and hygiene facilities, and limited access to health services make this vulnerable population particularly susceptible to a COVID-19 outbreak.

Design A descriptive, cross-sectional survey.

Setting Twelve IDP camps across six areas of the Lower Shabelle region in Somalia.

Participants 401 adult Somali IDP camp residents.

Results The majority of participants were female ( $86 \%)$ and had received no formal education (89\%). While $58 \%$ reported being in 'good' health, half of the participants reported having one or more pre-existing conditions. Though $77 \%$ of respondents reported taking at least one COVID-19 preventative public health measure, respondents reported a lack of access to adequate sanitation, an inability to practice social distancing and nearly universal inability to receive a COVID-19 screening exam. Questions assessing knowledge surrounding COVID-19 prevention and treatment yielded answers of 'I don't know' for roughly $50 \%$ of responses. The majority of participants were not familiar with basic information about the virus or confident that they could receive medical services if infected. 185 $(47 \%)$ respondents indicated that camp living conditions needed to change to prevent the spread of COVID-19.

Conclusion This study highlights low levels of COVID-19 knowledge and limited access to essential prevention and treatment resources among individuals living in Somali IDP camps. A massive influx of additional resources is required to adequately address COVID-19 in Somalia, starting with codesigning interventions to educate those individuals most vulnerable to infection.

\section{INTRODUCTION}

According to the United Nations High Commissioner for Refugees, there are more than 41 million internally displaced persons

\section{Strengths and limitations of this study}

- To the best of our knowledge, this study is one of the first to explore knowledge and perceptions of COVID-19, access to essential services and COVID-19 symptoms and risk factors among individuals living in internally displaced person (IDP) camps in any African country, including Somalia.

- This study drew on a diverse and expansive set of measures and involved a relatively large sample of IDPs that are often understudied and neglected in public health research, especially during the COVID-19 pandemic.

- Respondent health profiles collected in this study rely on self-reported data, which may introduce bias.

- Participants were recruited from 12 Somali IDP camps across six areas of the Lower Shabelle region and were predominantly women, which may limit the generalisability of the study findings.

(IDPs) and 25 million refugees globally. ${ }^{1}$ Many of those displaced live in camp settings with conditions that undermine public health guidelines for the control of infectious diseases, making them especially vulnerable to an outbreak of COVID-19. ${ }^{2}$ Additional legal, financial and linguistic barriers often inhibit displaced residents from accessing their host country's healthcare system, exacerbating conditions precipitated by an absence of basic amenities, such as soap, running water and medical supplies. ${ }^{2}$ Eighty-four per cent of displaced people reside in low- and middle-income countries, which are often ill equipped to institute health management protocols and mobilize response teams within IDP communities. ${ }^{3}$ Providing continuity of care for chronic conditions as well as infection prevention measures are necessary to 
ensure the well-being of both displaced and host communities. $^{24}$

The Ministry of Health in Somalia announced the first confirmed case of COVID-19 in Somalia on 16 March $2020 .^{5}$ As of 6 April, 2021, the Ministry of Health of Somalia reported 11,908 confirmed COVID-19 cases, 568 of which have resulted in death. ${ }^{5}$ It is well established that Somalia's health system is extremely underprepared for a further outbreak of COVID-19. ${ }^{6}$ In Somalia, 30 years of civil war and natural disasters have resulted in nearly 3 million IDPs who now inhabit over 2,100 overcrowded settlements. ${ }^{7}$ The prolonged conflict has severely damaged Somalia's health infrastructure, leaving its inhabitants vulnerable to climate-related disasters, malnourishment, infectious disease outbreaks and other humanitarian crises. ${ }^{89}$

Somalis face several barriers in accessing their country's healthcare system. Several reports inculcate that healthcare worker shortages and a non-existent health information system leave its residents without reliable access to care. ${ }^{89}$ Somali physicians have indicated that there are no ventilators and only two intensive care units with a total of 31 beds across the country, which is alarming given that these resources are regarded as necessary to treat severe COVID-19 infections. ${ }^{10}$ In addition, two in three Somalis have difficulties accessing safe water, and approximately $50 \%$ of health centres do not have reliable access to electricity. ${ }^{11}{ }^{12}$ Qualitative reports signal that care-seeking behaviour is also very poor among Somalis as a result of distrust towards the system's lack of regulation and unaffordable prices. ${ }^{13}$ Consequently, Somalia has some of the lowest health indicators in the world with life expectancies of 54 years for males and 57 years for females. ${ }^{11} 14$ Studies in Somalia have reinforced a predisposition of IDPs to infectious and water-borne diseases. ${ }^{15}$ IDPs are among the most vulnerable to infectious disease outbreaks as they face circumstances such as overcrowding, uncontained sewage and waste, limited access to health services, contaminated water, low immunisation coverage and stigmatisation.

According to the Global Health Security Index, Somalia ranks 194th out of 195 countries in preparedness for a globally catastrophic biological event. ${ }^{16}$ To address the dire threat COVID-19 poses to IDPs in Somalia, ongoing efforts have primarily focused on scaling up water, sanitation and hygiene (WASH) services, increasing monitoring and disseminating information about COVID-19. ${ }^{6} 7$ 17-19 Many organisations have also helped obtain equipment such as personal protective equipment and ventilators for providers, as well as soap and chlorine tablets for community members. ${ }^{71019}$ Several organisations have reported that the country's health system has no capacity to make early case detections, to isolate and care for patients and to conduct contact tracing. Thus, efforts have primarily focused on preventive measures to mitigate the virus's impact. $^{13}$
Among these efforts, few have incorporated IDP knowledge and perceptions of COVID-19 in their planning and implementation. Studies in IDP camps similar to those in Somalia warn of the profound consequences of COVID-19 in areas without a strong healthcare infrastructure, and various international health authorities have drawn attention to the grave threat the pandemic poses to these vulnerable populations. ${ }^{20-22}$ An international information gap about IDP knowledge and perceptions of COVID-19 exists and inhibits providers from implementing sustainable and culturally appropriate health interventions. As such, this study examined knowledge and perceptions of COVID-19, prevalence of pre-existing conditions and access to essential health services among residents of IDP camps in Somalia. We hope that our study findings contribute to the development of potential interventions to improve the response to COVID-19 in Somali IDP camps, where some of the world's most vulnerable individuals reside.

\section{METHODS}

\section{Design and instrument}

A descriptive, cross-sectional survey was used to assess the current health profile, living conditions, and knowledge and perceptions surrounding COVID-19 among adults living in Somali IDP camps. Survey questions were designed using published WHO and Centers for Disease Control and Prevention (CDC) information on COVID-19 symptoms and transmission, a 2019 Displacement Severity Assessment conducted among forcibly evicted Somalis and two published studies evaluating COVID-19 knowledge in Bangladesh and Nepal. ${ }^{23-27}$ Additionally, questions specific to the Somali and IDP contexts were included.

The first section of the survey focuses on demographic information, including sex, age, displacement status, household characteristics, education and employment. Response options for educational status reflect the education system in Somalia, including an option for Qur'anic education. The next section focuses on participants' health profiles, with questions probing current health status, existing conditions and symptoms. This section also includes a 12-item tool to gauge concerns brought about by COVID-19, such as potential effects on mental well-being, contracting COVID-19 or ability to buy essential food items. The third section of the survey assesses knowledge of COVID-19, most commonly used outlets for information, trusted sources of COVID-19 information and perceptions of community efforts against COVID19. An open-ended question on COVID-19 knowledge was followed by a 23-item tool that assesses knowledge of COVID-19 and consists of true-or-false statements regarding key facts or misconceptions surrounding the disease. The final section of the survey evaluates access to WASH, COVID-19 screening and health services.

Because participants did not speak English, this survey tool was translated into Somali. Though this survey was 
not assessed for reliability or validity, the Somali version of the survey was piloted in the Somali IDP context and reviewed for its content and suitability. Minor changes to the language of the Somali version were made to improve readability.

\section{Sample and setting}

A convenience sample of 401 individuals living in 12 Somali IDP camps across six areas (Ceelasha, Lafoole, Xaawo Cabdi, Carbiska and Afgooye) of the Lower Shabelle region in Somalia, often referred to as the world's capital of IDPs, was obtained in June 2020. Participants must have been older than 18 years of age, physically able to complete the survey and willing to take part in the study. A brief presentation of the purpose, procedure and requirements for participation was given privately to each participant. Prior to the survey being intervieweradministered by multilingual and trained staff from the Hagarla Institute, verbal consent was obtained. The Hagarla Institute is a non-profit organisation dedicated to furthering clinical research, capacity building and skills transfer for medical personnel across Africa. Participants were informed that they had the right to withdraw at any time and that there would be no consequences for withdrawal. All information collected was kept confidential and anonymised.

\section{Data analysis}

Responses from each survey were manually input onto Qualtrics survey software in English and analysed using SAS Studio V.3.8. ${ }^{28}$ Sample descriptive statistics were used to report median and SD calculations for continuous variables, along with frequency and percentages of responses for categorical variables.

\section{RESULTS}

\section{Sample demographics}

The demographic characteristics of survey participants are shown in table 1 . Of the 401 eligible participants, 382 $(96 \%)$ identified as IDPs and $15(4 \%)$ identified as refugees. The vast majority of participants were female $(86 \%$, $\mathrm{n}=344$ ), and the median age of the participants was 32.0, with a SD of 13.2 years. Most participants either had no formal education (89\%, $\mathrm{n}=353$ ) or received Qur'anic education $(32 \%, \mathrm{n}=126)$, with only 10 participants $(3 \%)$ having received education past secondary school.

Participant perceptions of their health status, preexisting health conditions, use of nicotine substances and COVID-19 symptoms are displayed in table 2. While $58 \%$ $(n=224)$ reported being in 'good' health and only $3 \%$ $(n=13)$ reported using cigarettes or tobacco products, $50 \%$ $(n=197)$ of participants reported having one or more of the listed pre-existing conditions. In regard to COVID-19 symptoms experienced, headache $(49 \%, \mathrm{n}=188)$ and fever (23\%, n=88) were most common. Furthermore, participant concerns arising from COVID-19 are displayed in table 3. Sixty-three per cent $(n=243)$ of respondents were

\begin{tabular}{lc}
\hline Table 1 Respondent characteristics & \\
\hline Characteristic & N (\%) $\dagger$ \\
\hline Sex & \\
\hline Female & $344(86.2)$ \\
\hline Male & $55(13.8)$ \\
\hline Age & $32.0 \pm 13.2$ \\
\hline Status & \\
\hline IDP & $382(96.2)$ \\
\hline Refugee & $15(3.8)$ \\
\hline \# of people in household & $7 \pm 5.1$ \\
\hline \# of people in household over 65 years & $0 \pm 3.0$ \\
\hline House or dwelling & \\
\hline Own & $97(24.3)$ \\
\hline Rent & $38(9.5)$ \\
\hline Not sure & $265(66.3)$ \\
\hline Highest level of education & \\
\hline No formal education & $353(88.7)$ \\
\hline Primary school & $26(6.5)$ \\
\hline Lower secondary school & $5(1.3)$ \\
\hline Upper secondary school & $4(1.0)$ \\
\hline Postsecondary/tertiary school & $7(1.8)$ \\
\hline $\begin{array}{l}\text { Graduate degree (eg, master's, } \\
\text { doctorate) }\end{array}$ & $3(0.8)$ \\
\hline Qur'anic education & $126(31.7)$ \\
\hline Work in the past 7 days & $190(47.5)$ \\
\hline Yes & $210(52.5)$ \\
\hline No & \\
\hline
\end{tabular}

*Values are frequency (percentage) for categorical variables; median \pm SD for continuous variables.

†Values may not add to $100 \%$.

IDP, internally displaced person.

concerned about getting adequate physical exercise, and $66 \%(\mathrm{n}=259)$ were worried about getting COVID-19. When asked how COVID-19 has changed their daily lives, 235 participants $(59 \%)$ indicated that the nationwide lockdown as a result of COVID-19 had decreased their income or caused them to lose their job (not shown). In addition, approximately $10 \%(\mathrm{n}=37)$ of respondents expressed concerns surrounding social dynamics and conflict within the household stemming from COVID-19.

\section{KNOWLEDGE AND PERCEPTIONS OF COVID-19}

Table 4 presents participant responses to true or false questions surrounding COVID-19. Roughly 50\% of responses to the question series were 'I don't know'. The majority of participants indicated that they did not know the current possible treatment $(83 \%, \mathrm{n}=327)$, symptoms $(50 \%, \mathrm{n}=201)$ or incubation period of COVID-19 (79\%, $\mathrm{n}=313)$, and $60 \%(\mathrm{n}=237)$ reported being unfamiliar with social distancing (not shown). Similarly, 63\% ( $n=250)$ 
Table 2 Respondent health profiles

\begin{tabular}{|c|c|}
\hline Characteristic & $\mathbf{N}(\%)^{*} \dagger$ \\
\hline \multicolumn{2}{|l|}{ Perception of health status } \\
\hline Good & $224(57.6)$ \\
\hline Fair & $101(26.0)$ \\
\hline Poor & $64(16.5)$ \\
\hline \multicolumn{2}{|l|}{ Pre-existing health conditions } \\
\hline Diabetes & $5(1.6)$ \\
\hline Anaemia & 76 (23.6) \\
\hline Hypertension & $5(1.4)$ \\
\hline $\begin{array}{l}\text { Lung disease (Chronic obstructive } \\
\text { pulmonary disease) }\end{array}$ & $3(0.8)$ \\
\hline
\end{tabular}

\begin{tabular}{lc} 
Cancer & $1(0.3)$ \\
\hline Asthma & $7(1.8)$ \\
\hline Malaria & $52(14.1)$ \\
\hline Dengue fever & $3(0.8)$ \\
\hline Oral/tooth disease & $7(1.8)$ \\
\hline Disability or injury from accident & $18(4.7)$ \\
\hline Sexually transmitted infection or fertility & $84(23.4)$ \\
\hline
\end{tabular}

\begin{tabular}{lc} 
Mental illness or psychiatric condition & $2(0.6)$ \\
\hline Other health condition & $36(10.0)$ \\
\hline Use of tobacco or cigarettes & $13(3.3)$ \\
\hline Yes & \\
\hline Exhibiting symptoms & $188(48.5)$ \\
\hline Headache & $88(23.0)$ \\
\hline Fever & $23(6.0)$ \\
\hline Skin rash & $19(5.0)$ \\
\hline $\begin{array}{l}\text { Dry cough } \\
\text { Wet cough or sputum/mucus production }\end{array}$ & $5(1.3)$ \\
\hline Sore throat & $10(2.6)$ \\
\hline Runny nose or nasal congestion & $3(0.8)$ \\
\hline New loss of taste and/or smell & $19(4.9)$ \\
\hline Shortness of breath or difficulty breathing & $10(2.6)$ \\
\hline $\begin{array}{l}\text { Diarrhoea } \\
\text { Muscle or body aches }\end{array}$ & $9(2.3)$ \\
\hline $\begin{array}{l}\text { Fatigue or malaise } \\
\text { One of the following: fever, dry cough and } \\
\text { fatigue }\end{array}$ & $52(13.6)$ \\
\hline $\begin{array}{l}\text { Two of the following: fever, dry cough and } \\
\text { fatigue }\end{array}$ & $22(59(12.8)$ \\
\hline $\begin{array}{l}\text { All of the following: fever, dry cough and } \\
\text { cough and fatigue }\end{array}$ & $6(1.8)$ \\
\hline
\end{tabular}

*Values are frequency (percentage).

†Values may not add to $100 \%$.

did not know that asymptomatic individuals could spread the virus. However, a sizeable proportion of participants were able to recognise headache $(34 \%, \mathrm{n}=135)$, fever $(45 \%, \mathrm{n}=179)$, cough $(35 \%, \mathrm{n}=139)$ and shortness of breath or difficulty breathing $(31 \%, \mathrm{n}=12)$ as symptoms of COVID-19 (not shown). Still, the proportion of participants who were not familiar with basic background information surrounding COVID-19 was higher than the proportion who answered questions correctly.

Participants most used and trusted sources of information surrounding COVID-19 are displayed in table 5. About $49 \% \quad(n=190)$ and $57 \% \quad(n=225)$ of participants reported that they trusted religious officials and the radio, respectively, to provide information about COVID19 , while only $37 \%(n=144)$ and $5 \%(n=19)$ said that they trusted health officials and humanitarian aid workers, respectively. Ninety percent $(\mathrm{n}=360)$ of participants reported receiving information on COVID-19 from traditional media services (radio, television and newspapers). A majority of respondents indicated that they felt that healthcare workers and the government were working together 'moderately' or 'a lot' to prevent the spread of COVID-19 (table 6). However, only 4\% (n=11) of respondents stated that they would go to health information providers in IDP camps if they suspected they had contracted the virus (not shown).

\section{Access to treatment and preventative services}

Table 7 reports participants' access to essential services, preventative resources and treatments for COVID-19. A majority lacked access to washing facilities $(71 \%, \mathrm{n}=277)$, soap $(67 \%, \mathrm{n}=256)$, disinfectants $(98 \%, \mathrm{n}=382)$ and face masks $(89 \%, \mathrm{n}=373)$. Although respondents lacked access to such resources, they still reported carrying out basic preventative procedures such as washing hands more often $(74 \%, \mathrm{n}=292)$ and avoiding shaking hands $(57 \%$, $\mathrm{n}=222) \quad($ not shown). While only $5 \%(\mathrm{n}=20)$ and $25 \%$ $(n=98)$ of participants reported using more disinfectants and practising social distancing, $77 \%(\mathrm{n}=296)$ reported having taken at least one preventative action (not shown). Moreover, 34\% ( $\mathrm{n}=135)$ of respondents reported not being able to buy essential food items in the last week. Of those, $74 \%(\mathrm{n}=100)$ reported having either to skip and eat smaller meals or buy lower quality food (not shown).

Additionally, 185 (47\%) respondents indicated that camp living conditions needed to change to prevent the spread of COVID-19 (not shown). In short answer responses, $142(80 \%)$ respondents expressed desires for improved sanitation, hygiene or housing conditions, and $14(8 \%)$ specifically indicated their desire for more stringent social distancing practices. However, $40 \% \quad(n=159)$ indicated that it would be impossible to self-isolate if taken ill (not shown).

Furthermore, respondents' self-reported access to COVID-19 screening and medical services was low, with 97\% $(\mathrm{n}=381)$ saying that they could not access screening and only $20 \% \quad(n=79)$ stating that they were confident that they could receive medical services if infected. Participants reported accessibility issues, with $48 \% \quad(n=191)$ stating that there was no healthcare facility nearby. Of those, $31 \% \quad(n=61)$ said that it would take over an hour to reach a healthcare facility (not shown). About $59 \%$ of 
Table 3 Concerns brought on by COVID-19

\begin{tabular}{|c|c|c|c|}
\hline Question & $\begin{array}{l}\text { Yes } \\
\text { n }(\%)^{\star} \dagger\end{array}$ & $\begin{array}{l}\text { No } \\
\text { n }(\%)^{\star} \dagger\end{array}$ & $\begin{array}{l}\text { Not sure } \\
\text { n }(\%)^{\star} \dagger\end{array}$ \\
\hline Getting adequate exercise/movement & $243(62.6)$ & 135 (34.8) & $10(2.6)$ \\
\hline Job security & $198(51.2)$ & $155(40.1)$ & $34(8.8)$ \\
\hline Social distancing & $71(18.7)$ & $292(77.0)$ & $16(4.2)$ \\
\hline Caring for children & $36(9.5)$ & 332 (87.6) & $11(2.9)$ \\
\hline The education of your child(ren) & $45(11.6)$ & $330(85.3)$ & $12(3.1)$ \\
\hline Social dynamics/conflict within the home & $37(9.6)$ & $271(70.0)$ & $79(20.4)$ \\
\hline Worried about getting COVID-19/coronavirus & $259(65.6)$ & $99(25.1)$ & $37(9.4)$ \\
\hline
\end{tabular}

*Values are frequency (percentage).

†Values may not add to $100 \%$.

participants indicated that they had received a vaccination for any condition in the past few years $(n=232)$ (not shown), and only $54 \%(\mathrm{n}=215)$ expressed that vaccines were accessible to them.

\section{DISCUSSION}

This study is the first to explore knowledge and perceptions of COVID-19, access to essential services and COVID-19 symptoms and risk factors among individuals living in IDP camps in Somalia. To our knowledge, it is also one of few studies that document knowledge of COVID-19 and prevalence of COVID-19 symptoms and risk factors among displaced populations globally. Overcrowding, limited access to WASH services and a lack of health infrastructure leave displaced populations living in IDP camps particularly vulnerable to the spread of infectious disease such as COVID-19. ${ }^{2}$

\section{Respondent health profile}

A considerable proportion of our sample reported experiencing symptoms that could potentially be attributed to COVID-19, including headache, fever, or muscle or body aches. ${ }^{29}$ Previous studies on health profiles of displaced populations living in such settings are unavailable in Somalia and are sparse in international settings, limiting the potential for cross-comparison. However, compared with a similar study conducted in refugee camps in Bangladesh, our sample exhibited higher proportions of individuals experiencing fevers, headaches, shortness of breath, loss of taste or smell, and muscle or body aches. ${ }^{27}$ In addition, our study findings reinforce concerns put forward in the literature regarding the spread of COVID-19 in humanitarian settings, including adequate exercise, mental health and well-being, job security, social distancing, conflict within the home and food insecurity.
These concerns should serve as priority areas for health and social service providers to engage with and address.

Though the rate of tobacco and cigarette use in our sample appears to be consistent with smoking prevalence in Somalia, especially when considering the majority of our sample consisted of women, our study found a lower rate of tobacco use when compared with other studies conducted in similar limited-resource settings ${ }^{3031}$ Furthermore, although little information is available regarding the health conditions of individuals living in IDP camps globally, self-reported pre-existing conditions from our sample appear to be considerably low, particularly for chronic and mental health conditions, when compared with values expected from the literature. ${ }^{32-35}$ Health staff administering surveys reported that many participants did not know what the surveyed conditions were, had little recollection of previous diagnoses and had rarely visited a health professional in the past. This is consistent with the significant lack of formal education among participants and lack of access to health facilities and may explain the lower reported prevalence of chronic, pre-existing conditions found in this study.

\section{Knowledge and perceptions of COVID-19}

This study found very poor knowledge related to COVID-19 and relevant universal safety measures among individuals living in Somali IDP camps. Though there is limited literature on this topic, especially in camp-like or humanitarian contexts, our sample exhibited significantly poorer knowledge of COVID-19 and safety measures, as compared with studies conducted in China, the USA, the UK and Nepal. ${ }^{26}{ }^{36} 37$ Although related literature in humanitarian settings is severely limited, this disparity persists in the sparse COVID-related published research in camp-like settings, such as that of a study conducted in Cox's Bazar, Bangladesh. ${ }^{27}$ These findings may be 
Table 4 Knowledge of COVID-19

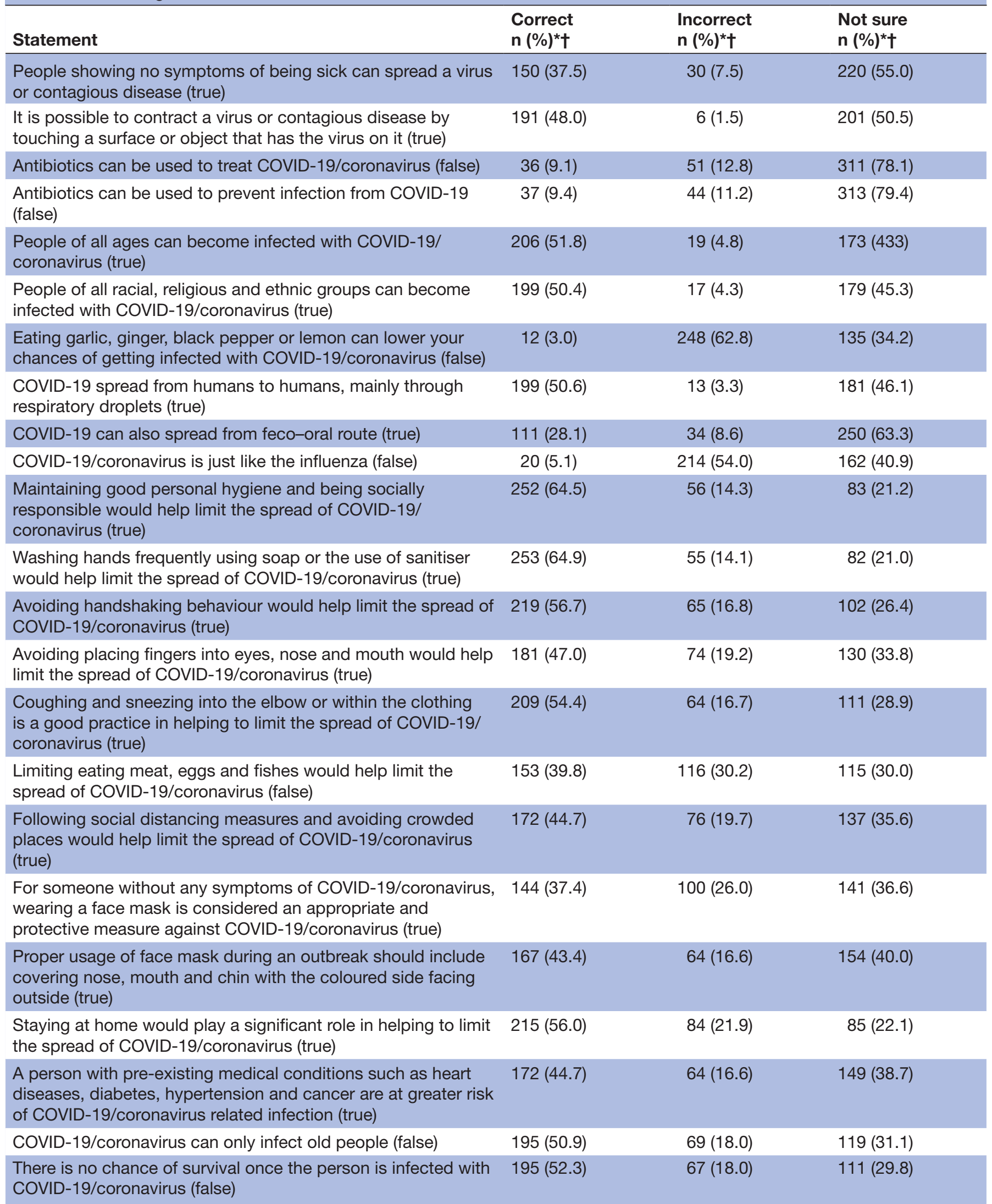

*Values are frequency (percentage).

†Values may not add to $100 \%$. 
Table 5 Respondent trusted sources of information surrounding COVID-19

\begin{tabular}{|c|c|}
\hline Source & n (\%)* \\
\hline \multicolumn{2}{|l|}{ Sources of information } \\
\hline $\begin{array}{l}\text { News, media (eg, TV, radio and } \\
\text { newspapers) }\end{array}$ & $360(90.0)$ \\
\hline Informational calls/SMS & $161(40.3)$ \\
\hline $\begin{array}{l}\text { Social media (eg, Facebook, Twitter, } \\
\text { WhatsApp, YouTube, Instagram and } \\
\text { Snapchat) }\end{array}$ & $21(5.3)$ \\
\hline $\begin{array}{l}\text { Official government/international } \\
\text { websites (eg, Ministry of Health, } \\
\text { WHO and CDC) }\end{array}$ & $10(2.5)$ \\
\hline $\begin{array}{l}\text { Family members, colleagues and } \\
\text { friends }\end{array}$ & $38(10.0)$ \\
\hline $\begin{array}{l}\text { Employer, work colleagues, and } \\
\text { others at work }\end{array}$ & 7 (1.8) \\
\hline Non-governmental organisations & $21(5.3)$ \\
\hline Informational campaigns & $17(4.3)$ \\
\hline Local or community leaders & $8(2.0)$ \\
\hline Journals & $8(2.0)$ \\
\hline
\end{tabular}

Trust in sources to provide COVID-19 information

\begin{tabular}{lc} 
Family members & $162(41.3)$ \\
\hline Religious official & $190(48.5)$ \\
\hline Community elder & $31(8.0)$ \\
\hline Health official & $144(36.7)$ \\
\hline Humanitarian aid worker & $19(4.8)$ \\
Social media & $17(4.3)$ \\
Web news & $9(2.3)$ \\
Television & $41(10.5)$ \\
\hline Radio & $225(57.4)$ \\
\hline
\end{tabular}

*Values are frequency (percentage).

attributed to the lack of formal education among study participants and the reality that Somalia has some of the lowest health and health literacy indicators in the world, which stem from decades of conflict, civil strife and limited access to healthcare and education, particularly for displaced populations like IDPs. ${ }^{38-41}$

The importance of education as a preventative measure in controlling the transmission of COVID-19 in camp settings cannot be understated. Given significant gaps in COVID-19 knowledge among Somali IDP camp residents, instituting precautionary measures, including public awareness campaigns, is of paramount importance. Knowledge is a critical determinant of health behaviours, and through targeted educational interventions, IDP camp residents can play an essential role in preventing community spread of the virus. ${ }^{42}$ Through highly used information platforms identified in this study, such as news and media outlets and informational calls or text messages, educational programmes can be codesigned with those living in IDP camps to address COVID-19 knowledge gaps, to disseminate information about COVID-19 prevention and treatment and to build trust between health providers and IDPs. Similarly, trusted sources, such as religious officials and the radio, can be mobilised to engage with community members and to dispel misinformation about COVID-19.

\section{Access to treatment and preventative services}

Our study reveals a significant lack of access to treatment and preventative services for COVID-19 among individuals living in IDP camps, which is consistent with other assessments of access to health and WASH services in Somalia and camp-like settings in other countries. $^{2}{ }^{43-45}$ Of particular note, the lack of access to COVID-19 screening tests suggests that cases may go undetected and spread rapidly within overcrowded camp settings. Similarly, our sample's reported lack of access to any vaccines may inhibit adequate uptake of a COVID-19 vaccine among this vulnerable population. These findings reflect the lack of access to services necessary to prevent COVID-19 transmission and suggest a lack of access to services that may exacerbate known comorbidities of COVID-19, such as hypertension, cancer, cardiovascular disease and diabetes, which are increasingly difficult to provide continuous care for during the COVID-19 pandemic. ${ }^{14}$ Generally, respondents reported limited confidence that they would be able to be treated if they contracted the virus, as well as an inability to participate in preventative measures due to a lack of material resources such as face masks and disinfectants, lack of information about COVID-19 prevention measures and inadequate living conditions to enforce social distancing protocols. Consistent with similar studies conducted with displaced populations in the Democratic Republic of the Congo and Syria, these

Table 6 Faith in community action against COVID-19

\begin{tabular}{|c|c|c|c|c|}
\hline Question & Not at all* & Somewhat* & Moderately* & A lot* \\
\hline
\end{tabular}

*Values are frequency (percentage). 
Table 7 Essential resources for COVID-19 response

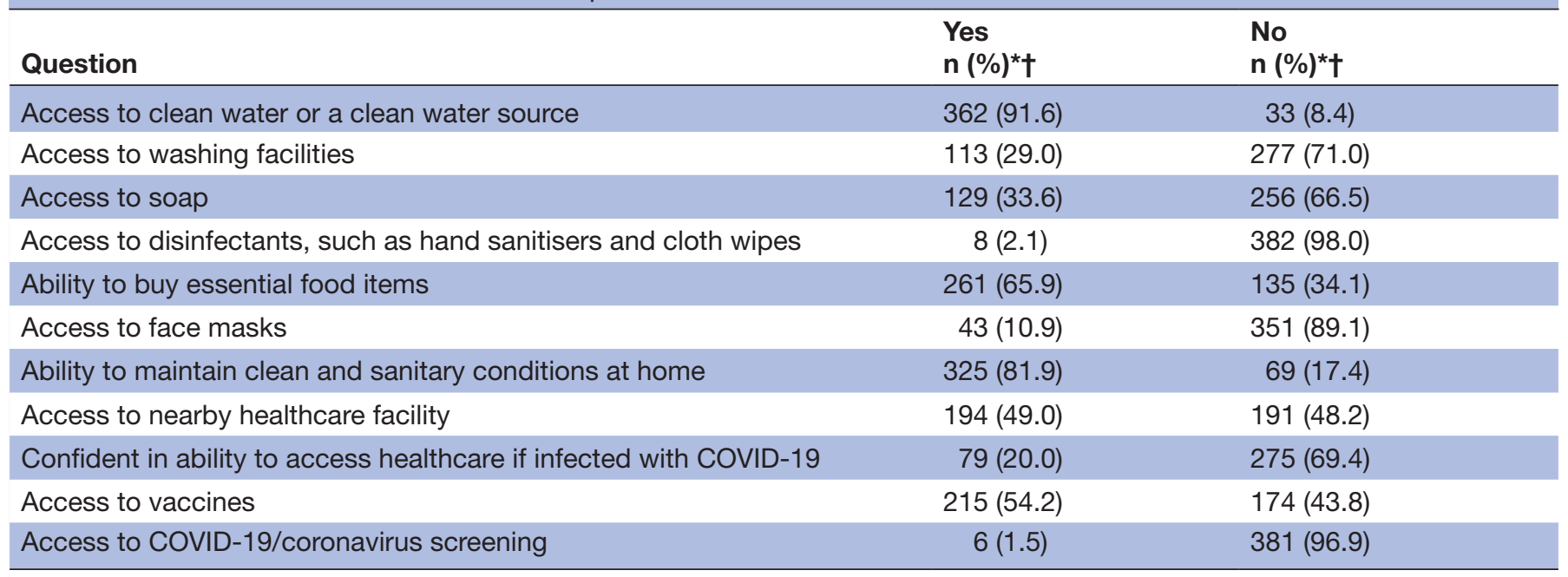

*Values are frequency (percentage).

†Values may not add to $100 \%$.

findings reinforce the necessity for substantial investment in improving access to health and WASH services for those living in camps, beginning with providing consumables such as soap and face masks to implement COVID-19 safety precautions and individual family accommodations such as tarpaulin tents to allow IDPs to practice distancing measures. ${ }^{46} 47$

\section{Limitations}

This study's sampling methodology is subject to several limitations. First, participants were recruited from 12 Somali IDP camps across six areas (Ceelasha, Lafoole, Xaawo Cabdi, Carbiska and Afgooye) of the Lower Shabelle region, which limits the generalisability of the study findings to IDP camps in other areas of Somalia. That being said, the Lower Shabelle region harbours one of the largest IDP populations in Somalia, as well as one of the highest concentrations of individuals in need of humanitarian support. ${ }^{48}$ Similarly, our analysis did not disaggregate data by IDP camp. Future studies should identify the challenges faced by IDP communities outside of the Lower Shabelle region and should explore circumstances unique to each camp setting, such that tailored interventions can be effectively designed. Second, because an overwhelming majority of participants surveyed $(86.2 \%)$ were women, the generalisability of the study results to males living in IDP camps may be limited. Third, the respondent health profiles reported (table 2) consist exclusively of self-reported data. As such, the limited reliability of participant responses for pre-existing conditions must be noted. Finally, given that this study uses a cross-sectional survey design, it cannot be used to analyse the evolution of COVID-19 knowledge, health conditions and access to services in Somali IDP camps over an extended period of time.

\section{CONCLUSION}

Ultimately, this study provides strong evidence for immense gaps in knowledge and perceptions of COVID-19 and access to treatment and preventative services among individuals living in Somali IDP camps. This study also provides insight into the health profile of IDP camp residents, as well as their concerns during the COVID-19 pandemic. A massive influx of additional resources and targeted interventions will be required to adequately address COVID-19 in Somalia, starting with educating those individuals most vulnerable to infection. Future research is needed to further elucidate the health profile of camp residents and the most at-risk individuals and to identify entry points to facilitate the implementation of COVID-19 prevention and treatment measures, taking into account the perspectives of IDP camp residents and relevant stakeholders. International organisations operating within Somalia, as well as the Somali government, should view investments in addressing COVID-19 as longterm investments in sustainable health infrastructure, as well as the health and prosperity of its population.

Twitter Mohamed Abdullahi Awale @Awale Abdullahi

Contributors JA, SA-A, LW, KK, MAA and DM contributed to the design of the study. MAA and DM contributed to the collection of data. JA, SA-A, LW, EW and NH each contributed to the analysis of data. All authors contributed to the interpretation of data and the development of the manuscript.

Funding The authors have not declared a specific grant for this research from any funding agency in the public, commercial or not-for-profit sectors.

Competing interests None declared.

Patient and public involvement Patients and/or the public were involved in the design, or conduct, or reporting, or dissemination plans of this research. Refer to the Methods section for further details.

Patient consent for publication Not required.

Ethics approval This study received approval from the ethics board at SIMAD University in Somalia and was deemed exempt from review by the Yale IRB (ID \#2000028344). Verbal consent to participate in the study was obtained privately 
from each participant prior to the survey being interviewer-administered by trained staff from the Hagarla Institute. If a participant consented, they were informed of their right to withdraw at any time without any consequences and were presented with a brief overview of the study before any survey questions were administered. All information collected was confidential and anonymised.

Provenance and peer review Not commissioned; externally peer reviewed.

Data availability statement All data relevant to the study are included in the article or uploaded as supplementary information.

Open access This is an open access article distributed in accordance with the Creative Commons Attribution Non Commercial (CC BY-NC 4.0) license, which permits others to distribute, remix, adapt, build upon this work non-commercially, and license their derivative works on different terms, provided the original work is properly cited, appropriate credit is given, any changes made indicated, and the use is non-commercial. See: http://creativecommons.org/licenses/by-nc/4.0/.

ORCID iD

Jude Alawa http://orcid.org/0000-0003-3600-4356

\section{REFERENCES}

1 Hopman J, Allegranzi B, Mehtar S. Managing COVID-19 in low- and middle-income countries. JAMA 2020;323:1549-50.

2 Kluge HHP, Jakab Z, Bartovic J, et al. Refugee and migrant health in the COVID-19 response. The Lancet 2020;395:1237-9.

3 UNHCR The UN Refugee Agency. Global trends: forced displacement in 2017, 2018. Available: https://www.unhcr.org/ 5b27be547.pdf

4 Lau LS, Samari G, Moresky RT, et al. COVID-19 in humanitarian settings and lessons learned from past epidemics. Nat Med 2020;26:647-8.

$5 \mathrm{MOH}-$ Ministry of Health Somalia, 2020. Available: https://moh. nomadilab.org/

6 International Rescue Committee (IRC). Somalia faces another Desperate situation as COVID-19 cases spiral, IRC calls for increased support to save lives, 2020. Available: https://www.rescue. org/press-release/somalia-faces-another-desperate-situation-covid19-cases-spiral-irc-calls-increased

7 UNHCR. Somalia | COVID-19 response. Available: https://reporting. unhcr.org/sites/default/files/UNHCR\%20Somalia\%20COVID-19\% 20Response\%20Update\%20-\%2028APR20_0.pdf [Accessed 28 Apr 2020].

8 Ali AM, Handuleh J, Patel P, et al. The most fragile state: healthcare in Somalia. Med Confl Surviv 2014;30:28-36.

9 Warsame A, Handuleh J, Patel P. Prioritization in Somali health system strengthening: a qualitative study. Int Health 2016;8:204-10.

10 Somalia Responds, International Organization for Migration. Somalia responds: together we can fight COVID-19 in Somalia. Available: https://www.iom.int/donate/campaigns/somalia-responds

11 World Health Organization. World Health organization humanitarian response plans in 2015: Somalia, 2015. Available: https://www.who. int/hac/donorinfo/somalia.pdf

12 Elkheir N, Sharma A, Cherian M, et al. A cross-sectional survey of essential surgical capacity in Somalia. BMJ Open 2014;4:e004360.

13 Gele AA, Ahmed MY, Kour P, et al. Beneficiaries of conflict: a qualitative study of people's trust in the private health care system in Mogadishu, Somalia. Risk Manag Healthc Policy 2017;10:127-35.

14 World Health Organization. Somalia, 2020. Available: https://www. who.int/countries/som/en/

15 Soliman AA, Abdulrahman BMA, Abdalla Ali J, et al. Water associated diseases amongst children in IDPs camps and their relation to family economics status: case study of Abuschock IDPs camp, North Darfur state, Sudan. International Journal of Research -GRANTHAALAYAH 2017;5:214-27.

16 Global Health Security Index: Building Collective Action and Accountability p. 274, "Somalia", 2019. Available: https://www. ghsindex.org/wp-content/uploads/2020/04/2019-Global-HealthSecurity-Index.pdf

17 Operational Portal, UNHCR. Document - CCCM COVID-19 Contingency Plan, 2020. Available: https://data2.unhcr.org/en/ documents/details/75050

18 Kumamaru K, Khayre O, Ito C. Improving access to safe water for internally displaced persons (IDPs) in a fragile state, Somalia, 2013Loughborough University. Available: https://hdl.handle.net/ $2134 / 30919$
19 International Committee of the Red Cross. Somalia: critical juncture to curb spread of COVID-19 and save lives, 2020. Available: https:// www.icrc.org/en/document/somalia-critical-juncture-curb-spreadcovid-19-and-save-lives

20 Truelove S, Abrahim O, Altare $\mathrm{C}$, et al. The potential impact of COVID-19 in refugee camps in Bangladesh and beyond: A modeling study. PLoS Med 2020;17:e1003144.

21 Bigg MM. Support for internally displaced people needs to be 'urgently stepped up', 2020. Available: https://www.unhcr.org/en-us/ news/latest/2020/4/5e9839e74/support-internally-displaced-peopleneeds-urgently-stepped.html

22 United Nations Human Rights Office of the High Commissioner OHCHR. COVID-19: do not forget internally displaced persons, UN expert urges Governments worldwide, 2020. Available: https://www. ohchr.org/EN/NewsEvents/Pages/DisplayNews.aspx?NewsID=25763

23 World Health Organization. Coronavirus, 2020. Available: www.who. int/health-topics/coronavirus

24 Centers for Disease Control and Prevention. Symptoms of coronavirus, 2020. Available: www.cdc.gov/coronavirus/2019-ncov/ symptoms-testing/symptoms.html

25 Wesolek P, Sydney C, Crowley M. Assessing the severity of displacement. Internal displacement monitoring centre, 2020. Available: www.internal-displacement.org/sites/default/files/ publications/documents/Severity\%20Report\%202019.pdf

26 Singh DR, Sunuwar DR, Karki K, et al. Knowledge and perception towards universal safety precautions during early phase of the COVID-19 outbreak in Nepal. J Community Health 2020;45:1116-22.

27 Lopez-Pena P, Austin Davis C, Mushfiq Mobarak A. Prevalence of COVID-19 symptoms, risk factors, and health behaviors in host and refugee communities in Cox's Bazar: a representative panel study. Bull World Health Organ 2020;11.

28 Qualtrics L. Qualtrics [software]. Utah, USA Qualtrics; 2014.

29 Huang C, Wang Y, Li X, et al. Clinical features of patients infected with 2019 novel coronavirus in Wuhan, China. The Lancet 2020;395:497-506.

30 Reitsma MB, Fullman N, Ng M, et al. Smoking prevalence and attributable disease burden in 195 countries and territories, 19902015: a systematic analysis from the global burden of disease study 2015. The Lancet 2017;389:1885-906.

31 Jawad M, Khader A, Millett C. Differences in tobacco smoking prevalence and frequency between adolescent Palestine refugee and non-refugee populations in Jordan, Lebanon, Syria, and the West bank: cross-sectional analysis of the global youth tobacco survey. Confl Health 2016;10:20.

32 de Jong JP, Scholte WF, Koeter MW, et al. The prevalence of mental health problems in Rwandan and Burundese refugee camps. Acta Psychiatr Scand 2000;102:171-7.

33 Doocy S, Lyles E, Roberton T, et al. Prevalence and care-seeking for chronic diseases among Syrian refugees in Jordan. BMC Public Health 2015;15:1097.

34 Amara AH, Aljunid SM. Noncommunicable diseases among urban refugees and asylum-seekers in developing countries: a neglected health care need. Global Health 2014;10:24.

35 Alawa J, Maiky C, Khoshnood K, et al. Cancer prevention and treatment in humanitarian settings: an urgent and unmet need. Lancet Oncol 2019;20:1635-6.

36 Zhong B-L, Luo W, Li H-M, et al. Knowledge, attitudes, and practices towards COVID-19 among Chinese residents during the rapid rise period of the COVID-19 outbreak: a quick online cross-sectional survey. Int J Biol Sci 2020;16:1745-52.

37 Geldsetzer P. Knowledge and perceptions of COVID-19 among the general public in the United States and the United Kingdom: a crosssectional online survey. Ann Intern Med 2020;173:157-60.

38 Klutse V. Measuring Health Literacy Among Somali Men Over the Age of 45 - A Pilot Study. Master of Science in Nursing Theses 2014;12 http://digitalcommons.cedarville.edu/nursing_theses/12

39 Centers for Disease Control and Prevention. Refugee health profiles, 2018. Available: https://www.cdc.gov/immigrantrefugeehealth/ profiles/somali/background.html

40 Ferris E, Winthrop R, Humanitarian Library, The Brookings Institution Education and displacement: assessing conditions for refugees and internally displaced persons affected by conflict, 2010. Available: https://www.humanitarianlibrary.org/sites/default/files/2014/02/ 190715e.pdf

41 Drumtra J. Internal displacement in Somalia, 2014The Brookings Institution. Available: https://www.refworld.org/pdfid/54bd197b4.pdf

42 Kenkel DS. Health behavior, health knowledge, and schooling. $J$ Polit Econ 1991;99:287-305.

43 Ivanova O, Rai M, Kemigisha E. A systematic review of sexual and reproductive health knowledge, experiences and access to services among refugee, migrant and displaced girls and young women 
in Africa. Int J Environ Res Public Health 2018;15. doi:10.3390/ ijerph15081583. [Epub ahead of print: 2607 2018].

44 World Health Organization. Pandemic influenza preparedness and mitigation in refugee and displaced populations. WHO guidelines for humanitarian agencies, 2008. Available: https://www.who.int/csr/ resources/publications/swineflu/pandemic_preparedness_refugee/ en/

45 Blundell H, Milligan R, Norris SL, et al. WHO guidance for refugees in camps: systematic review. BMJ Open 2019;9:e027094-7.

46 Claude KM, Serge MS, Alexis KK, et al. Prevention of COVID-19 in internally displaced persons camps in War-Torn North Kivu,
Democratic Republic of the Congo: a mixed-methods study. Glob Health Sci Pract 2020;8:638-53.

47 Douedari Y, Alhaffar M, Al-Twaish M, et al. "Ten years of war! You expect people to fear a 'germ'?": A qualitative study of initial perceptions and responses to the COVID-19 pandemic among displaced communities in opposition-controlled northwest Syria. $J$ Migr Health 2020;1-2:100021.

48 ReliefWeb, UNOCHA. 2019 humanitarian needs overview: Somalia, 2018. Available: https://reliefweb.int/sites/reliefweb.int/files/ resources/Somalia_2019_HNO.PDF 